\title{
Effects of particle size on physicochemical and functional properties of superfine black kidney bean (Phaseolus vulgaris L.) powder
}

\author{
Xianbao Sun ${ }^{1,2}$, Yuwei Zhang ${ }^{3}$, Jing Li ${ }^{4}$, Nayab Aslam ${ }^{5}$, Hanju Sun ${ }^{1,2,6}$, Jinlong Zhao ${ }^{1}$, Zeyu Wu ${ }^{1,2}$, \\ Shudong He ${ }^{\text {Corresp. 1, 2, } 6}$ \\ ${ }^{1}$ School of Food and Biological Engineering, Hefei University of Technology, Hefei, China \\ 2 Engineering Research Center of Bio-process, Ministry of Education, Hefei University of Technology, Hefei, China \\ 3 School of Food Science and Engineering, Shaanxi Normal University, Xi'an, China \\ 4 Department of Biological and Environmental Engineering, Hefei University, Hefei, China \\ 5 Institute of Home \& Food Sciences, Government College University, Faisalabad, Pakistan \\ 6 Anhui Province Key Laboratory of Functional Compound Seasoning, Anhui Qiangwang Seasoning Food Co., Ltd., Jieshou, China \\ Corresponding Author: Shudong He \\ Email address: shudong.he@hfut.edu.cn
}

Black kidney bean (Phaseolus vulgaris L.) powder (BKBP) with particle sizes of 250-180, $180-125,125-75,75-38$, and < $38 \mu \mathrm{m}$ was prepared by using coarse and eccentric vibratory milling, respectively. Physicochemical properties, cholesterol adsorption, and antioxidant activities of powders were investigated. Size and SEM analyses showed that particle size of BKBP could be effectively decreased after the superfine grinding treatment, and the specific surface area was increased. Flow properties, hydration properties, thermal stability and cholesterol adsorption efficiency significantly improved with the reducing of particle size. The superfine powder with sizes of 75-38 or $<38 \mu \mathrm{m}$ exhibited higher antioxidant activity via DPPH, hydroxyl radical-scavenging, and ferrous ion-chelating assays. The results indicated that the BKBP with a size of $<38 \mu \mathrm{m}$ could serve as a better potential biological resource for food additives, and could be applied for the development of low-cholesterol products. 
5 Xianbao Sun $^{\mathrm{a}, \mathrm{b}, 1}$, Yuwei Zhang ${ }^{\mathrm{c}, 1}$, Jing Li ${ }^{\mathrm{c}, \mathrm{d}}$, Nayab Aslam ${ }^{\mathrm{e}}$, Hanju Sun ${ }^{\mathrm{a}, \mathrm{b}}$, Jinlong Zhao ${ }^{\mathrm{a}}$, Zeyu

$6 \mathrm{Wu}^{\mathrm{a}, \mathrm{b}}$, Shudong $\mathrm{He}^{\mathrm{a}, \mathrm{b}, *}$

$8 \quad$ a School of Food and Biological Engineering, Hefei University of Technology, Hefei, China

9 b. Engineering Research Center of Bio-process, Ministry of Education, Hefei University of

10 Technology, Hefei, China

$11{ }^{\mathrm{c}}$ School of Food Science and Engineering, Shaanxi Normal University, Xi'an, China

$12{ }^{\mathrm{d}}$ Department of Biological and Environmental Engineering, Hefei University, Hefei, China

13 e Institute of Home \& Food Sciences, Government College University, Faisalabad, Pakistan

$14 \mathrm{~g}$ Anhui Province Key Laboratory of Functional Compound Seasoning, Anhui Qiangwang

15 Seasoning Food Co., Ltd., Jieshou, China

17 * Correspondence: Shudong He, School of Food and Biological Engineering, Hefei University of 18 Technology, Hefei, China.

19 Tel: 86-551-62901505, Fax: 86 551-62901516, E-mail: shudong.he@hfut.edu.cn 


\section{ABSTRACT}

Black kidney bean (Phaseolus vulgaris L.) powder (BKBP) with particle sizes of 250-180,

$180-125,125-75,75-38$, and $<38 \mu \mathrm{m}$ was prepared by using coarse and eccentric vibratory milling, respectively. Physicochemical properties, cholesterol adsorption, and antioxidant activities of powders were investigated. Size and SEM analyses showed that particle size of BKBP could be effectively decreased after the superfine grinding treatment, and the specific surface area was increased. Flow properties, hydration properties, thermal stability and cholesterol adsorption efficiency significantly improved with the reducing of particle size. The superfine powder with

29 sizes of 75-38 or $<38 \mu \mathrm{m}$ exhibited a higher antioxidant activity via DPPH, hydroxyl radical-

30 scavenging, and ferrous ion-chelating assays. The results indicated that the BKBP with a size of $<$

$3138 \mu \mathrm{m}$ could serve as a better potential biological resource for food additives, and could be applied

32 for the development of low-cholesterol products. 


\section{INTRODUCTION}

As an essential crop, kidney beans (Phaseolus vulgaris L.) are particularly popular in Africa, Latin American, and Asia (Beninger \& Hosfield, 2003), and consumed as a human food source throughout the world representing $50 \%$ of the grain legumes (Camara et al., 2013). Potential benefits to human health have been explored during the kidney beans consumption, including lowering postprandial glucose and insulin responses, preventing obesity, reducing the risk of cardiovascular diseases and preventing cancers because of the high contents in protein, fiber, vitamin B, and chemically diverse micronutrient compositions (Ai et al., 2016; Anton et al., 2009; Mitchell et al., 2009). Furthermore, the phenols are rich in kidney beans, which will lead to greater anti-oxidative activity and will be beneficial for preventing oxidative damages (Camara et al., 2013; Lee \& Yoon, 2015).

Recently, due to the nutritional and economical values, kidney bean powders have been employed as a food ingredient in the manufacture of value-added products (Anton et al., 2009; Malav et al., 2016), however, the properties of BKBP have not been well documented to date. As a necessary process, controlling the particle size in the grinding process is of importance, as it will influence powder behaviors during storage, handling, and processing (Lee \& Yoon, 2015). Powder with a larger particle size might be unwieldy for extraction and leaching, and would lengthen heat treatment for blanching and/or cooking (Barbosa-Canovas et al., 2005). In addition, various changes in powder color, texture, and bioactive compounds as well as taste acceptability would be also dependent on variations of particle size (Lee \& Yoon, 2013; Liu et al., 2010; Zhu et al., 2010). Thus, searching for appropriate particle size for black kidney bean powder would be necessary to 
55

improve the application in nutraceuticals and functional food products, as well as a potential and novel biomaterial.

As a useful and novel process technology, superfine grinding has been widely applied in the ceramic, electric material, and chemical powder product developments due to the well contributions to surface effect, mini-size effect, mechanical property, and chemical and/or catalytic properties (Zhao et al., 2009b). Currently, because of the increasing processing requirements, superfine grinding methods, such as ball milling, jet milling, and high-pressure expansion, have begun to be applied in the food industry. Tan et al. (2015) reported that waxy and high-amylose corn starches had a lower viscosity and better pasting stability via planetary ball-milling. Phat et al. (2015) confirmed that Hericium erinaceum powder prepared via jet milling had good water solubility and swelling capacity, which would be suitable to manufacture instant and convenient foods. In the previous study, superfine okra powders exhibited a higher cholesterol adsorption capacity compared with the coarse (Chen et al., 2015b), indicating that the superfine powder might be a potential bio-absorbent for low-cholesterol food developments. It has also been reported that Astragalus membranaceus, wheat (Triticum aestivm L.) bran, and okra (Abelmoschus esculentus) superfine powders have an increased flowability (Chen et al., 2015b; He et al., 2018; Zhao et al., 2010). Several studies found that superfine grinding treatment could enhance the antioxidant activities of some food powders, such as red rice (Oryza sativa L.), Qingke (hull-less barley), and winter wheat (Triticum aestivm L.) bran superfine powders (Chen et al., 2015a; He et al., 2018; Zhu et al., 2015) through altering the molecular weight and solution behavior of bioactive components. However, Anguita et al. (2006) reported that a reduction in the particle size of barley 
76 after grinding was accompanied by a decrease of water retention capacity. Choi et al. (2018) and

77 Liu et al. (2015) found that increasing degrees of milling significantly reduced phenolics in rice flours. It has also reported that the antioxidant ability of wheat bran powder was coarse $>$ medium

79 > fine size (Brewer et al., 2014). Then, the reverse phenomena indicated the physicochemical properties seemed to be unpredictable, and would be related to particle size reduction, various grinding treatments, and raw materials. Thus, the effects of superfine grinding treatment on the physicochemical and functional properties of BKBP should be explored due to the little information. intensification of the impact force among the grinding rollers for improved effectivity (Gock \& Kurrer, 1999). In addition, the power consumption of eccentric vibratory milling is significantly decreased (up to $50 \%$ compared to conventional vibratory tube mills), due to the decrease of the ratio between kerb mass and payload, as well as the rational bearing load (Beenken et al., 1996), then it is increasingly used for fine grinding and pulverization of raw materials on an industrial scale (Baláž \& Dutková, 2009; Godočíková et al., 2006). Thus, the BKBP was developed via eccentric vibratory milling in this study, and the effects of particle size on physicochemical, microstructural, cholesterol adsorption, and antioxidant properties of the resulting powders were investigated. The results are favorable for the development of value-added products using the

BKBP.

MATERIAL AND METHODS

\section{Materials}


Black kidney beans (Phaseolus vulgaris L.) were obtained from a local supermarket in Hefei,

Anhui Province, China, and with a species authentication by Heilongjiang Crops Variety Examination Committee (Heilongjiang Province, China). Ferrozine, 2,2-Diphenyl-1picryhydrazyl radical (DPPH), ferrous sulfate, salicylic acid, and cholesterol were purchased from Sinopharm Chemical Reagents Co. (Shanghai, China). All other used chemicals were of analytical grade.

\section{Micronization processing of black kidney bean}

The dried black kidney beans were milled coarsely by a domestic disc-mill (DS-T200A model, Shanghai Dingshuai Electric Co., Ltd., Shanghai, China) for a $3 \mathrm{~min}$ discontinuous grinding, and then screened through 250-180 $\mu \mathrm{m}$ sieves. The resulting coarse samples were remilled through an eccentric vibratory mill (XDW-6J model, Jinan Micro Machinery Co., Ltd., Shandong, China) for $10 \mathrm{~min}$, and superfine powders with the particle sizes of $180-125,125-75$, 75-38 and $<38 \mu \mathrm{m}$ were then obtained via sieving. The eccentric vibratory mill was consisted of cylindrical-like elastically suspended grinding pipes, and kept the frequency of an unbalanced drive constant at $1000 \mathrm{rpm}$ during grinding. The circulating cold water was applied to maintain a low temperature.

\section{Particle size distribution and specific surface area analysis}

Particle size distribution of BKBP was analyzed via laser diffraction particle size analyzer (Mastersizer 2000, Malvern Instruments Ltd., Worcestershire, UK). The samples were dispersed in the ethanol before measured, and the volume weighted mean diameter of $D_{[4,3]}$, as well as the selected percentile points of $D_{10}, D_{50}$, and $D_{90}$, which represent 10,50 , and $90 \%$ volume of the 
118 particle mass diameter that is smaller than the size indicated, respectively, was used to characterize

119 the particle size distribution of the superfine powder. The specific surface area $\left(\mathrm{m}^{2} / \mathrm{g}\right)$ was also

120 calculated based on the volume distribution by the particle size analyzer.

121 Scanning electron microscopy (SEM) analysis

122

Morphological characterization of the BKBP particles was performed using scanning electron

123

microscope (SEM) (JSM-6490LV, JEOL Ltd., Tokyo, Japan) at an operating voltage of $20 \mathrm{kV}$

with working distance of $11 \mathrm{~mm}$.

125

126

127

128

129

130

131

132

133

134

135

136

137

138

\section{Color analysis}

The color of sample was detected via an automatic color difference meter (WB2000-IXA, Shanghai Exact Science Instrument Ltd., Shanghai, China) using the Hunter scale of $L^{*}, a^{*}$, and $b^{*}$ values as indicators.

\section{Flow property analysis}

The flow properties of BKBP were determined via bulk density $(\mathrm{g} / \mathrm{mL})$, tapped density $(\mathrm{g} / \mathrm{mL})$, angle of repose $\left(^{\circ}\right)$, and angle of slide $\left(^{\circ}\right)$ using a powder integrative characteristic testing instrument (BT-1000, Bettersize Instruments Ltd., Liaoning, China) (He et al., 2018).

\section{Water holding capacity (WHC) and water retention capacity (WRC) analyses}

The WHC was determined using the method of Zhao et al. (2010). The weights of cleaned centrifuge tubes $\left(\mathrm{M}_{0}\right)$ and dry BKBP samples $\left(\mathrm{M}_{1}\right)$ were measured, and the samples were then dispersed in the water with a ratio of $0.05: 1(\mathrm{w} / \mathrm{w})$ and incubated at $60{ }^{\circ} \mathrm{C}$ for $10,20,30,40,50$, and $60 \mathrm{~min}$, respectively. After centrifugation for $20 \mathrm{~min}$ at $5000 \mathrm{rpm}$, the supernatant was removed, and the centrifuge tubes with the powder $\left(\mathrm{M}_{3}\right)$ were weighed. The WHC of BKBP was 
calculated as follows:

$$
\mathrm{WHC}(\mathrm{g} / \mathrm{g})=\left(\mathrm{M}_{3}-\mathrm{M}_{0}-\mathrm{M}_{1}\right) / \mathrm{M}_{1}
$$

WRC was defined as the quantity of water that remains bound to the hydrated fiber following application of an external force. The samples $\left(\mathrm{M}_{3}\right)$ were dried at $105^{\circ} \mathrm{C}$ for $2 \mathrm{~h}$, and then weighed $\left(\mathrm{M}_{4}\right)$ again to calculate the WRC as follows:

$$
\mathrm{WRC}(\mathrm{g} / \mathrm{g})=\left(\mathrm{M}_{3}-\mathrm{M}_{4}\right) / \mathrm{M}_{4}
$$

\section{Thermal property analysis}

The thermal property was analyzed via the differential scanning calorimetry (DSC) method using a TA ultrasensitive differential scanning microcalorimeter (Model TA Q200, TA Instruments Co., New Castle, DE, USA). Eight milligrams of each sample were put into a hermetic aluminum pan and heated from 20 to $220^{\circ} \mathrm{C}$ at a rate of $10^{\circ} \mathrm{C} / \mathrm{min}$ in a $50 \mathrm{~mL} / \mathrm{min}$ nitrogen flow, using an empty aluminum pan as reference. Each curve obtained by the instrument was further analyzed via Universal Analysis 2000 software (TA Instruments Co., New Castle, DE, USA).

\section{Cholesterol adsorption capacity analysis}

The cholesterol adsorption capacity was expressed as the quality of adsorbed cholesterol for per gram of BKBP, which was estimated by the method of Chen et al. (2015b). The cholesterol solution with different concentrations was prepared in glacial acetic acid. The BKBP was added in cholesterol solution with a selected mass ratio, and then placed in a shaker water bath at $37^{\circ} \mathrm{C}$ for $90 \mathrm{~min}$ at $90 \mathrm{rpm}$. At the end of adsorption, $2 \mathrm{~mL}$ of the supernatant were used for cholesterol estimation. The cholesterol adsorption capacity was calculated using the following formula:

$$
\text { Cholesterol adsorption capacity }(\mathrm{mg} / \mathrm{g})=\left[\mathrm{V}\left(\rho_{0}-\rho\right)\right] / \mathrm{m}
$$


Where $\mathrm{V}$ represents the volume of the cholesterol solution, $\rho_{0}$ and $\rho$ represent the

161

162 concentrations of cholesterol solution before and after adsorption, respectively, and $\mathrm{m}$ represents the weight of BKBP. Effects of the particle size, powder dosage, initial concentration of cholesterol, absorption time, and absorption temperature on cholesterol adsorption capacity were evaluated.

\section{Antioxidant activity analysis}

The antioxidant activity was determined via the scavenging activities of 2,2-Diphenyl-1picrylhydrazyl (DPPH) and hydroxyl free radicals. Two milliliters of BKBP solution $(5 \mathrm{mg} / \mathrm{mL})$ were mixed with $2.5 \mathrm{~mL}$ DPPH-ethanol solution $(100 \mu \mathrm{M})$ for a $30 \mathrm{~min}$ reaction at $37^{\circ} \mathrm{C}$. Then, the mixture was centrifuged at $10000 \mathrm{rpm}$ for $10 \mathrm{~min}$, and the absorbance of the supernatant $\left(\mathrm{Abs}_{\text {sample }}\right)$ was recorded at $517 \mathrm{~nm}$. Blank absorbance $\left(\mathrm{Abs}_{\text {blank }}\right)$ was measured using methanol to replace the sample. Vitamin $\mathrm{C}\left(\mathrm{V}_{\mathrm{C}}, 5 \mathrm{mg} / \mathrm{mL}\right)$ was used as positive control. The DPPH radical scavenging activity $(\%)$ was calculated using the equation of $\left[\left(\mathrm{Abs}_{\mathrm{sample}}-\mathrm{Abs}_{\mathrm{blank}}\right) / \mathrm{Abs}_{\mathrm{blank}}\right] \times$ 100\% (Andrade et al., 2017).

The hydroxyl radical scavenging activity (\%) was estimated following a previously reported method (Zhao et al., 2015). Two milliliters of BKBP solution $(5 \mathrm{mg} / \mathrm{mL})$ was used for testing. The reaction mixture solution was centrifuged at $10000 \mathrm{rpm}$ for $10 \mathrm{~min}$ to determine the absorbance of the supernatant at $510 \mathrm{~nm}$. Methanol was applied to determine the blank absorbance $\left(\mathrm{Abs}_{\mathrm{blank}}\right)$, and the hydroxyl radical scavenging activity $(\%)$ of BKBP was calculated by $\left[\left(\mathrm{Abs}_{\text {sample }}-\mathrm{Abs}_{\mathrm{blank}}\right) /\right.$ $\left.\mathrm{Abs}_{\text {blank }}\right] \times 100 \%$.

In addition, the $\mathrm{Fe}^{2+}$ chelating capacity was also measured. One milliliter of BKBP solution 
$181(5 \mathrm{mg} / \mathrm{mL})$ was mixed with $2 \mathrm{M} \mathrm{FeCl}_{2}$ solution $(0.1 \mathrm{~mL})$ under addition of $0.2 \mathrm{~mL}$ of $5 \mathrm{mM}$

182 ferrozine and was left standing for $10 \mathrm{~min}$. The supernatant after centrifugation was recorded at

$183517 \mathrm{~nm}$ and the reaction mixture without sample was used as a blank $\left(\mathrm{Abs}_{\text {blank }}\right)$; then, the $\mathrm{Fe}^{2+}$

184 chelating activity (\%) was obtained via the equation of $\left[\left(\mathrm{Abs}_{\text {sample }}-\mathrm{Abs}_{\text {blank }}\right) / \mathrm{Abs}_{\text {blank }}\right] \times 100 \%$

185 (He et al., 2018).

186

187

188

189

190

191

192

193

194

195

196

197

198

199

200

201

\section{Statistical analysis}

All experiments were repeated and analyzed at least in triplicate. Results were expressed as the mean $\pm \mathrm{SD}$, and one-way analysis of variance (ANOVA) was employed to determine the significant differences between the means at $P<0.05$ using SPSS version 13.0 (SPSS Inc., Chicago, IL, USA).

\section{RESULTS}

\section{Particle properties and microphotographs of BKBP}

The particle size distribution and specific surface area of BKBP were presented in Table 1. With particle size decreasing, all cumulative undersize centiles $\left(D_{10}, D_{50}\right.$, and $\left.D_{90}\right)$ of BKBP significantly $(P<0.05)$ decreased. $D_{[4,3]}$ values of the powder decreased from 226.658 to 24.835 $\mu \mathrm{m}$ for a particle size ranging from 250-180 to $<38 \mu \mathrm{m}$ (Table 1). Furthermore, the specific surface area increased with the decrease of particle size, and the BKBP with the smallest particle size $(<$ $38 \mu \mathrm{m})$ showed the highest specific surface area of $0.520 \mathrm{~m}^{2} / \mathrm{g}$, suggesting that the surface parameter of BKBP was negatively related to the projected size of the corresponding particle.

The shape and surface morphology of BKBP were observed using SEM (Fig. 1). As the particles size decreased, it was possible to see the transition of typical blocky shape (coarse 
202

203

204

205

206

207

208

209

210

211

212

213

214

215

216

217

218

219

220

221

222

powder) into short ones (Fig.1c, 125-75 $\mu \mathrm{m}$ ), until very small parts and fragments were achieved

(Figs.1d and e, $<38 \mu \mathrm{m}$ ). From Figs. 1b to e, with the improvement of mechanical force, the transformation of BKBP from an ordered structure to a disordered structure was clearly presented via the breakage of intermolecular bonds as well as the reduction of particle size. It was notable that Figs. 1d to e exhibited an increased aggregation of BKBP, due to the various shapes of black kidney bean particles resulted from the extensive milling combination of flattening, aggregation and fracture. Under the higher magnification (Figs. 1f-j), it could be clearly seen that the particles surface tends to be flat and smooth with the size decreasing.

\section{Color}

As listed in Table 2, $L^{*}$ increased slightly $(P<0.05)$ when the BKBP size decreased from 250-180 to $75-38 \mu \mathrm{m}$, and no significant difference $(P>0.05)$ in lightness was found between the sample sizes of 75-38 $\mu \mathrm{m}$ and $<38 \mu \mathrm{m}$. Furthermore, an increase in $a^{*}$ value could be observed, but it was difficult to visually obtain due to the smaller variance. The $b^{*}$ value decreased from 30.654 to 15.805 with BKBP size decreasing from $250-180$ to $125-75 \mu \mathrm{m}$, while increasing to 35.653 at the particle size $<38 \mu \mathrm{m}$.

\section{Flow property}

To evaluate the flowability of BKBP, the powder integrative characteristics were analyzed. As the particle size decreased from $250-180$ to $<38 \mu \mathrm{m}$, the bulk density decreased from 0.439 to $0.364 \mathrm{~g} / \mathrm{mL}$, and the largest bulk density $(0.439 \mathrm{~g} / \mathrm{mL})$ was found in the particle size of $250-180$ $\mu \mathrm{m}$ (Table 2). In contrast, the tapped density of BKBP increased from 1.435 to $2.645 \mathrm{~g} / \mathrm{mL}$ with BKBP size decreasing from 250-180 to $<38 \mu \mathrm{m}$. The values of tapped density were significantly 
223 higher than the bulk density. Moreover, the angle values of repose and slide decreased significantly $224(P<0.05)$ with the reduction of particle size. The BKBP with a particle size of $<38 \mu \mathrm{m}$ had the 225 lowest angles of repose $\left(43.282^{\circ}\right)$ and slide $\left(33.259^{\circ}\right)$.

226

227

228

229

230

231

232

233

234

235

236

237

238

239

240

241

242

243

\section{Hydration property}

The hydration property of BKBP was determined by WHC and WRC assays. With the reduction of particle sizes from 250-180 to $<38 \mu \mathrm{m}$, the WHC values of BKBP increased, ranging from 5.98 to $6.26 \mathrm{~g} / \mathrm{g}, 6.03$ to $6.87 \mathrm{~g} / \mathrm{g}, 6.18$ to $7.41 \mathrm{~g} / \mathrm{g}, 6.28$ to $7.86 \mathrm{~g} / \mathrm{g}, 6.31$ to $7.81 \mathrm{~g} / \mathrm{g}$, and 6.44 to $8.03 \mathrm{~g} / \mathrm{g}$ for $10,20,30,40,50$, and $60 \mathrm{~min}$ of soaking (Fig. 2a), respectively. A similar tendency was also found in the WRC assay for the BKBP under the same soaking conditions (Fig. 2b). Thus, the hydration property of the BKBP with a particle size of $<38 \mu \mathrm{m}$ was higher. It was also worth mentioning that the WHC values of different sized BKBP increased slowly during the initial 10 min soaking.

\section{Thermal property}

The thermal property of BKBP with different sizes was further analyzed via DSC curves (Fig.

3). Compared to the endothermic peaks $\left(T_{m}\right)$ observed in the curve of coarse powder, the peak around $97.07{ }^{\circ} \mathrm{C}$ disappeared in the analyses of superfine powder with sizes of $180-125,125-75$, 75-38 and $<38 \mu \mathrm{m}$. Notably, an intense endothermic peak was found from 128.56 to $178.10{ }^{\circ} \mathrm{C}$ in all curves, and the peak temperatures exhibited a significant increasing tendency with the decreasing of particle size.

\section{Cholesterol adsorption of BKBP}

As shown in Fig. 4a, the adsorption capacity for cholesterol significantly increased with the 
244 reduction of particle size. The BKBP with a size of $<38 \mu \mathrm{m}$ showed the strongest adsorption

245 capacity $(27.27 \mathrm{mg} / \mathrm{g})$; thus, it was chosen for further evaluation. The cholesterol adsorption 246 capacity decreased dramatically from 26.95 to $15.51 \mathrm{mg} / \mathrm{g}$ with adsorbent dosage increasing (Fig.

247 4b). With the increase in initial concentration of cholesterol, the adsorption capacity increased

248 (Fig. 4c). Furthermore, the cholesterol adsorption capacity for different adsorption time (min) and temperature $\left({ }^{\circ} \mathrm{C}\right)$ was shown in Figs. $4 \mathrm{~d}$ and e, respectively. The adsorption increased quickly with increasing time from 10 to $60 \mathrm{~min}$, reaching a plateau in the following $60-150 \mathrm{~min}$ (Fig. 4d); nevertheless, the cholesterol adsorption capacity decreased when temperature increased (Fig. 4e).

252

253

254

255

256

257

258

259

260

261

262

263

264

\section{Adsorption isotherms analysis}

The relationship between the adsorption capacity $\left(\mathrm{q}_{\mathrm{e}}\right)$ and the concentration of cholesterol at equilibrium $\left(\mathrm{C}_{\mathrm{e}}\right)$ was further analyzed via fitting to Langmuir and Freundlich isotherms models, respectively (Ngah \& Hanafiah, 2008). The Langmuir model is considered as a monolayer adsorption processing, which assumes monolayer adsorption onto an adsorbent surface. The linear equation is given by $1 / \mathrm{q}_{\mathrm{e}}=\left[1 /\left(\mathrm{K}_{\mathrm{L}} \times \mathrm{q}_{\max }\right)\right] /\left(1 / \mathrm{C}_{\mathrm{e}}\right)$, where $\mathrm{q}_{\max }$ represents the maximum adsorption capacity $(\mathrm{mg} / \mathrm{g}), \mathrm{C}_{\mathrm{e}}$ represents the concentration of adsorbate $(\mathrm{mg} / \mathrm{mL})$ at equilibrium, and $\mathrm{K}_{\mathrm{L}}$ represents a constant related to energy of adsorption, which quantitatively reflects the affinity between adsorbent and adsorbate. The maximum adsorption capacity of cholesterol adsorption was calculated as $53.476 \mathrm{mg} / \mathrm{g}$ for BKBP (Table 3). Moreover, the essential feature of the Langmuir model was expressed with a dimensionless constant separation factor $\left(R_{L}\right)$, which was calculated using the equation of $1 /\left(1+\mathrm{K}_{\mathrm{L}} \times \mathrm{C}_{0}\right)$, where $\mathrm{C}_{0}$ represents the initial cholesterol concentration $(\mathrm{mg} / \mathrm{mL})$. Therefore, the $\mathrm{R}_{\mathrm{L}}$ was $0.370-0.804$ for the initial cholesterol concentration 
265

266

267

268

269

270

271

272

273

274

275

276

277

278

279

280

281

282

283

284

285

\section{3}

ranging from 0.25 to $1.50 \mathrm{mg} / \mathrm{mL}$, respectively, indicating a favorable adsorption of cholesterol using the BKBP (Fig. 4f).

The Freundlich isotherm model was considered to be multilayer adsorption and could be suitable to highly heterogeneous surface, which could be expressed with the linear equation of $1 \mathrm{~g}$ $\mathrm{q}_{\mathrm{e}}=\mathrm{Ce} / \mathrm{n}+\lg \mathrm{K}_{\mathrm{F}}$, where $\mathrm{K}_{\mathrm{F}}$ and $\mathrm{n}$ represent the Freundlich constants indicative of the adsorption capacity and intensity, respectively. The value of $1 / \mathrm{n}$ determined via the Freundlich isotherm was $0.697(1 / \mathrm{n}<1)$ (Table 3$)$, confirming the high adsorption efficient of BKBP.

\section{Antioxidant activity analysis}

The antioxidant activity of the BKBP with different particle sizes was evaluated by different in vitro assays (Fig. 5). Regarding radical scavenging activity using DPPH assay, the finer powders with particle sizes of 75-38 and $<38 \mu$ m exhibited higher DPPH scavenging activities of $87.30 \pm$ 1.77 and $89.40 \pm 0.81 \%$, respectively (Fig. 5a). As shown in Fig. 5b, the powder with particle size of $75-38 \mu \mathrm{m}$ exhibited the strongest hydroxyl radical scavenging activity $(88.92 \pm 1.38 \%)$ among all tested samples, while the BKBP with the particle size of $250-180 \mu \mathrm{m}$, obtained via coarse grinding, showed the lowest activity $(69.72 \pm 2.49 \%)$ (Fig. 5b). Furthermore, an increase in ferrous ion-chelating effects was observed when the particle size decreased from 250-180 to 75-38 $\mu \mathrm{m}$, and the BKBP with a size of $75-38 \mu$ m exhibited the strongest chelating activity of $81.16 \pm 1.72 \%$ (Fig. 5c).

\section{DISCUSSION}

Taking into account the nutritional and economical aspects of black kidney beans, fortifying 
varied bean powders appears to be promising for the production of health food (Lee et al., 2008).

287 Conventional milling methods have generally been used in the pulverization and research of

kidney bean (Anton et al., 2009; Malav et al., 2016). However, until now, systematic studies on superfine kidney bean powder are still limited.

In the present study, BKBP with sizes between 180 to $<38 \mu \mathrm{m}$ was prepared via eccentric vibratory mill. Elliptical, circular and linear vibrations could be generated via eccentric vibratory mill instead of homogeneous circular vibrations, which would increase the amplitude of the individual grinding media and increase the rotational speed of the grinding media filling (Gock \&

Kurrer, 1999). Consequently, as shown in the particle size and SEM analyses (Table 1 and Fig. 1),

BKBPs were efficiently broken into smaller fractions, and the shape and original structure of

particles were changed to be smoother by the inhomogenous impact force. Therefore, physicalchemical properties of BKBP would be altered with the sieving of special size parameters (250$180,180-125,125-75,75-38$, and $<38 \mu \mathrm{m})$, confirmed the importance of micronization equipment on the fluidity, dissolution, and surface activity of powders (Muttakin et al., 2015).

The color parameters of BKBP (Table 2) depicted their relations to particle size and morphology. The increase of $L^{*}$ values was as expected with the reduction of particle size, due to the increase in surface area, and that would allow more reflection of light (Ahmed et al., 2016).

Meanwhile, the loss of pigment and the exposure of internal materials during superfine grinding also could contribute to the improvement of brightness. Thus, the BKBP with a size of $<38 \mu \mathrm{m}$ was brighter, which might be favorable for the applications as food ingredients. The decrease of 
307 of inter-particulate interactions, which indicated the improvement of flowability of the BKBP.

308 Moreover, according to Table 2, the decreasing angle of repose and slide of superfine BKBP with smaller size also might indicate the increase of flowability (Zhao et al., 2010). But the result was not in agreement with the investigation of Lee \& Yoon (2015), who found that the soybean powders with the smallest particle size $(250-150 \mu \mathrm{m})$ showed a poor flowability because of the cohesion. However, Fu et al. (2012) reported that powder shape significantly affected the flow characteristics of the powder, and stated that more circular and smooth shaped particles had the higher flowability, which was consistent with our results for the morphology analysis (Fig. 1), and confirmed the efficiency of eccentric vibratory mill. Thus, the BKBP with a size of $<38 \mu \mathrm{m}$ had a

larger number of particles per unit weight and achieved the higher flowability, which would be

beneficial to fill tablets or capsule products to achieve homogeneity state when mixed with other additives.

of BKBP. Particles with a size of $<38 \mu \mathrm{m}$ exhibited the highest hydratability during soaking (Fig.

2), which was higher than previous data on soybean flours $(4.1 \mathrm{~g} / \mathrm{g})($ Heywood et al., 2002) and

superfine wheat (Triticum aestivm L.) bran superfine powder (7.0 g/g) (He et al., 2018). Superfine

grinding treatment might result in the surface properties changes of the BKBP, such as the increase

of surface energy, greater surface area, and the exposure of hydrophilic groups, which led to an 
328 al. (2009a). In contrast, Raghavendra et al. (2006) found that the hydration properties of coconut

329 dietary fiber were decreased when its particle size was decreased from 550 to $390 \mu \mathrm{m}$. It has been

330 reported that grinding the dry fibrous material to fine powder adversely affected its WHC and

331 swelling capacity, presumably attributed to the collapse of the fiber matrix by milling

332 (Kethireddipalli et al., 2002). Hence, various physicochemical characteristic would be discovered

333 because of the diversity of materials and grinding treatments. Eccentric vibratory milling treatment

might result in the damage on BKBP structure, and the particle size would be too smaller to

compensate differences on the hydration properties. High hydration capacities of BKBP would

increase the affinity between the powder and water, and might keep more water in the inner part

(He et al. 2018), which would lead to the enhancement of evaporation energy, and exhibited an

improved thermal stability (Fig. 3). Therefore, BKBP with the smaller size (such as $<38 \mu \mathrm{m}$ ) could

be more suitable for water retention, and might thus be more potentially applied as functional

ingredient to prevent syneresis and improve textural properties, as well as be utilized in the higher-

temperature processing, such as baking or steaming.

It is well known that the surplus cholesterol in the human body forms an initial pathogenic

factor of arteriosclerosis, resulting in apoplectic stroke, angina pectoris, and cardio sclerosis (Soh

et al., 2003). Food material as biosorbent for cholesterol reducers/extractors is of growing interest,

due to many advantages, such as natural, wide availability, healthy, and nontoxicity. Good

cholesterol binding capacities have been found using the cereal brans, such as rice bran, oat bran,

wheat bran, and corn bran (Kahlon \& Chow, 2007). Adsorption properties of four legume seeds

348 (green lentil, white small bean, yellow pea, and yellow soybean) have been evaluated by Górecka 
349 et al. (2003), grinding degree was found to be significantly influenced the adsorption properties.

350 In the present study, superfine BKBP was found to have a high cholesterol adsorption capacity by

351 in vitro assays, which was probably correlated with their high contents of dietary fiber, especially

352 hemicelluloses and lignin (Górecka et al., 2003), thus it could be recommended in the in lipid

353 disorders prophylactic. Particle size, powder dosage, initial concentration of cholesterol,

354 absorption time, and absorption temperature were all found to significantly affected the cholesterol

adsorption of BKBP (Fig. 4). Decreasing particle size could effectively improve cholesterol

adsorption capacity of BKBP due to the increase of specific surface area, thus lead to a larger

contact area with cholesterol and shorter absorbing path distance (Chen et al., 2015b). It was

interesting that the relative lower temperature would be favorable for the cholesterol adsorption,

thus cholesterol adsorption process using BKBP should be controlled at below $18{ }^{\circ} \mathrm{C}$ for a 60 min

reaction.

Furthermore, the maximal adsorption capacity $(53.476 \mathrm{mg} / \mathrm{g})$ of BKBP was successfully

predicted by Langmuir adsorption isotherms analysis (Table 3), which was higher than the ability

of okra superfine powder around $18.75 \mathrm{mg} / \mathrm{g}$ (Chen et al., 2015b), and carrot pomace insoluble

dietary fiber around $30 \mathrm{mg} / \mathrm{g}$ (Yu et al., 2018), but lower than thyme (Thymus vulgaris L.) powder

of $84.74 \mathrm{mg} / \mathrm{g}$ (Salehi et al., 2018). Besides, the value of 1/n (0.697) obtained from the Freundlich

model was less than unity, indicating the favorability of the adsorption. The two fitting models

suggested that BKBP would be effective as a potential adsorbent. Therefore, it seemed that the

BKBP could be applied in the functional food manufactures, such as biscuits and other healthy

products, to reduce calories and cholesterol without loss in physical and structural properties 
370 (Prokopov, 2014). It has been confirmed that the plant source of seed powder might have

371 hypolipidemic and anti-nephrotoxic effects in cadmium-treated rats (Ajilore, 2018). Thus,

372 superfine BKBP might act as a novel nutraceutical additive/excipient in tablets, such as

373 simvastatin, to provide synergistic effects for lowering serum cholesterol level (Swami et al.,

374 2010). Besides, it would be also interesting to employ the BKBP as the potential biosorption

375 materials in the developments of low cholesterol milk or milk beverages (Oliveira et al., 2015),

376 and even in the extracorporeal perfusion to immediately reduce the content of the lipids in the

377 blood (Salehi et al., 2018).

378 In addition, multiple antioxidant assays including DPPH and hydroxyl radical scavenging

activity, as well as ferrous ion-chelating effects, were carried out in the experiments, and particle

sizes showed significant effects on the activities (Fig. 5). The capability of stable free radical 2,2-

diphenyl-1-picrylhydrazyl to react with H-donors, including phenolics in natural materials, could

be evaluated by the DPPH• test in the visible region after a fixed incubation time (Roginsky \&

Lissi, 2005; Lopez-Alarcon et al., 2013). In this study, higher DPPH• scavenging activity was

obtained with the decrease of BKBP particle size (Fig. 5a). Meanwhile, the powder with a particle

size of 75-38 $\mu \mathrm{m}$ exhibited the strongest hydroxyl radical scavenging activity in Fig. 5b. Hydroxyl

radicals $(\bullet \mathrm{OH})$ are the most commonly formed reactive oxygen species (ROS) and have been

linked to many clinical disorders, such as brain ischemia, cardiovascular disease, and

carcinogenesis (Hu et al., 2012). Several reports also indicated that the $\bullet \mathrm{OH}$ scavenging effects

could be related to hypoglycemic activity (Chen et al., 2009; Chen et al., 2005). As shown in Fig.

$5 \mathrm{c}$, the ferrous ion $\left(\mathrm{Fe}^{2+}\right)$-chelating activity of the BKBP was favorably affected by the reduction 
391

392

393

394

of particle size, which would prevent the generation of free radicals, oxyradicals, and lipid peroxidation (Singh \& Rajini, 2004).

According to the previous studies, polyphenols and flavonoids compounds were main antioxidant compounds presenting in kidney bean (Phaseolus vulgaris L.), containing free and bound forms (Cardador-Martínez et al., 2002; Malav et al., 2016). Meanwhile, as one kind of black coat bean, a high accumulation of anthocyanins relating to antioxidant activity would be found in the epidermis palisade layer, and was up to 13955 (mg CGE/kg) (Žilić et al., 2013). Therefore, the increase of antioxidant availability in the BKBP with the smaller particle sizes (such as 75-38 and $<38 \mu \mathrm{m})$ might be attributed to the fact that finer particles would be beneficial for the dissolution of free-form antioxidant compounds. In addition, superfine grinding broke the structure of protein and fiber matrix (as shown in SEM images), and thus increased the availability of bound-form antioxidant compounds linked or embedded in the matrix. However, as shown in Figs. 5b and c, compared with the sample size of 75-38 $\mu \mathrm{m}$, the antioxidant activities of BKBP with a size of $<$ $38 \mu \mathrm{m}$ have a slight decrease $(P>0.05)$, which might be attributed to the inevitable mechanical impact and heating effect during superfine grinding, leading to altering or disrupting of antioxidant compounds within BKBP. Therefore, controlling grinding degree is of importance, as it will influence powders' functional properties, and superfine BKBP with a size of 75-38 $\mu \mathrm{m}$ exhibited a potential application as antioxidative products.

\section{CONCLUSIONS}

Fine BKBP with smooth surface was obtained using the eccentric vibratory milling, and the 
412 application potential of BKBP was improved with the decrease of particle size. The BKBP with a

413 particle size of $<38 \mu \mathrm{m}$ exhibited good flowability, hydration properties, and thermal stability.

414 Adsorption isotherm analysis highlighted the promising potential of the superfine BKBP with a

415 particle size of $<38 \mu \mathrm{m}$ as a cholesterol sorbent or an alternative source to absorb harmful lipids.

416 Moreover, compared with the other particle sizes, the superfine BKBP with sizes of $<75 \mu \mathrm{m}$

417 showed improved antioxidant activities in the free radical scavenging activities. Overall, the BKBP

418 prepared by eccentric vibratory mill with a particle size of $<38 \mu \mathrm{m}$ showed great potentials in the

419 food industry and pharmaceutical field for the health product developments. In the future, in vivo

420 evaluations of the BKBP would be urgently carried out, and the BKBP produced using the

421 eccentric vibratory mill should be further evaluated under various processing conditions to better

422 understand the attributes of the grinding technology.

423

424 ACKNOWLEDGEMENTS

425 We thank Prof. Zhaojun Wei, School of Food and Biological Engineering, Hefei University

426 of Technology, for the expertise and help during this research and members in our laboratory for

427 fruitful discussions. The authors are grateful to the anonymous reviewers' careful works and

428 thoughtful suggestions.

\section{REFERENCES}

430 Ahmed J, Taher A, Mulla MZ, Al-Hazza A, and Luciano G. 2016. Effect of sieve particle size on 431 functional, thermal, rheological and pasting properties of Indian and Turkish lentil flour. 
433 Ai YF, Cichy KA, Harte JB, Kelly JD, and Ng PKW. 2016. Effects of extrusion cooking on the chemical composition and functional properties of dry common bean powders. Food Chemistry 211:538-545 DOI: 10.1016/j.foodchem.2016.05.095.

436

437

438

439

440

441

442

443

444

445

446

447

448

449

450

451

452

453

Ajilore BS. 2018. Hypolipidaemic and Anti-nephrotoxic Effects of Crysophyllum albidum (African Star Apple) Seeds Extract in Cadmium-treated Rats. Society for Experimental Biology of Nigeria 18(2).

Andrade J, Denadai M, De CO, Nunes ML, and Narain N. 2017. Evaluation of bioactive compounds potential and antioxidant activity of brown, green and red propolis from Brazilian northeast region. Food Research International 101:129-138 DOI:10.1016/j.foodres.2017.08.066.

Anguita M, Gasa J , Martín-Orúe SM, and Pérez JF. 2006. Study of the effect of technological processes on starch hydrolysis, non-starch polysaccharides solubilization and physicochemical properties of different ingredients using a two-step in vitro system. Animal Feed Science and Technology 129(1-2):99-115 DOI: 10.1016/j.anifeedsci.2005.12.004.

Anton AA, Fulcher RG, and Arntfield SD. 2009. Physical and nutritional impact of fortificationof corn starch-based extruded snacks with common bean (Phaseolus vulgaris L.) flour: Effects of bean addition and extrusion cooking. Food Chemistry 113(4):989-996 DOI:10.1016/j.foodchem.2008.08.050.

Baláž P, and Dutková E. 2009. Fine milling in applied mechanochemistry. Minerals Engineering 22:681-694 DOI: doi.org/10.1016/j.mineng.2009.01.014. 
454 Barbosa-Canovas GV, Ortega-Rivas E, Juliano P, and Yan H. 2005. Food powders: physical properties, processing, and functionality. New York: Kluwer Academic/Plenum Publishers.

456

457

458

459

460

461

462

463

464

465

466

467

468

469

470

471

472

473

474 International Journal of Mineral Processing 44-45:437-446 DOI: doi.org/10.1016/03017516(95)00050-X.

Beninger CW, and Hosfield GL. 2003. Antioxidant activity of extracts, condensed tannin fractions, and pure flavonoids from Phaseolus vulgaris L. seed coat color genotypes. Journal of Agricultural \& Food Chemistry 51(27):7879-7883 DOI: 10.1021/jf0304324.

Brewer LR, Kubola J, Siriamornpun S, Herald TJ, and Shi YC. 2014. Wheat bran particle size influence on phytochemical extractability and antioxidant properties. Food Chemistry 152:483-490 DOI: 10.1016/j.foodchem.2013.11.128.

Camara CRS, Urrea CA, and Schlegel V. 2013. Pinto Beans (Phaseolus vulgaris L.) as a Functional Food: Implications on Human Health. Agriculture 3:90-111 DOI: 10.3390/agriculture3010090.

Cardador-Martínez A, Loarca-Piña G, and Oomah BD. 2002. Antioxidant activity in common beans (Phaseolus vulgaris L.). Journal of Agricultural \& Food Chemistry 50(24):69756980 DOI: 10.1021/jf020296n.

Chen H, Wang Z, Qu Z, Fu L, Dong P, and Zhang X. 2009. Physicochemical characterization and antioxidant activity of a polysaccharide isolated from oolong tea. European food research and technology 229(4):629-635 DOI: 10.1007/s00217-009-1088-y. 
conjugate from green tea. Food Chemistry 90(1-2):17-21 DOI: 10.1016/j.foodchem.2004.03.001.

477 Chen QM, Fu MR, Yue FL, and Cheng YY. 2015a. Effect of Superfine Grinding on Physicochemical Properties, Antioxidant Activity and Phenolic Content of Red Rice (Oryza sativa L.). Food \& Nutrition Sciences 06:1277-1284 DOI: 10.4236/fns.2015.614133.

481

482

483

484

485

486

487

488

489

490

491

492

493

494

495

Chen Y, Zhang BC, Sun YH, Zhang JG, Sun HJ, and Wei ZJ. 2015b. Physicochemical properties and adsorption of cholesterol by okra (Abelmoschus esculentus) powder. Food \& Function 6(12):3728-3736 DOI: 10.1039/c5fo00600g.

Choi S, Seo HS, Lee KR, Lee S, and Lee J. 2018. Effect of cultivars and milling degrees on free and bound phenolic profiles and antioxidant activity of black rice. Applied Biological Chemistry 61(1):49-60 DOI: 10.1007/s13765-017-0335-3.

Gock E, and Kurrer KE. 1999. Eccentric vibratory mills - theory and practice. Powder Technology 105(1-3):302-310 DOI: 10.1016/S0032-5910(99)00152-7.

Godočíková E, Baláž P, Gock E, Choi WS, and Kim BS. 2006. Mechanochemical synthesis of the nanocrystalline semiconductors in an industrial mill. Powder Technology 164:147-152 DOI: 10.1016/j.powtec.2006.03.021.

Górecka D, Korczak J, Flaczyk EJPJoF, and Sciences N. 2003. Adsorption of bile acids and cholesterol by dry grain legume seeds. Polish Journal of Food \& Nutrition Sciences 12(53):69-73.

He SD, Li J, He Q, Jian H, Zhang Y, Wang J, and Sun HJ. 2018. Physicochemical and antioxidant 
496

497

498

499

500

501

502

503

504

505

506

507

508

509

510

511

512

513

514 516 515 test of soybean powder. Food Chemistry 138(2-3):841-850 DOI:

properties of hard white winter wheat (Triticum aestivm L.) bran superfine powder produced by eccentric vibratory milling. Powder Technology 325:126-133 DOI: 10.1016/j.powtec.2017.10.054.

Heywood AA, Myers DJ, Bailey TB, and Johnson LA. 2002. Functional properties of extrudedexpelled soybean flours from value-enhanced soybeans. Journal of the American Oil Chemists' Society 79(7):699-702 DOI: 10.1007/s11746-002-0545-Z.

Hu JH, Chen YQ, and Ni DJ. 2012. Effect of superfine grinding on quality and antioxidant property of fine green tea powders. LWT - Food Science \& Technology 45(1): 8-12 DOI: 10.1016/j.lwt.2011.08.002.

Kahlon TS, and Chow FI. 2007. In Vitro Binding of Bile Acids by Rice Bran, Oat Bran, Wheat Bran, and Corn Bran. Cereal Chemistry 77(4):518-521 DOI: 10.1094/CCHEM.2000.77.4.518.

Kethireddipalli P, Hung YC, Phillips RD, and Mcwatters KH. 2002. Evaluating the role of cell wall material and soluble protein in the functionality of cowpea (Vigna unguiculata) pastes. Journal of Food Science 67(1):53-59 DOI: 10.1111/j.1365-2621.2002.tb11358.x.

Lee IH, Hung YH, and Chou CC. 2008. Solid-state fermentation with fungi to enhance the antioxidative activity, total phenolic and anthocyanin contents of black bean. International Journal of Food Microbiology 121(2):150-156 DOI: 10.1016/j.ijfoodmicro.2007.09.008.

4 Lee YJ, and Yoon WB. 2013. Effects of particle size and heating time on thiobarbituric acid (TBA) 10.1016/j.foodchem.2012.11.113. 
517 Lee YJ, and Yoon WB. 2015. Flow behavior and hopper design for black soybean powders by 518 particle size. Journal of Food Engineering 144:10-19 DOI: 10.1016/j.jfoodeng.2014.07.005.

520

521

522

523

524

525

526

527

528

529

530

531

532

533

534

535

536

537

Liu L, Guo JJ, Zhang RF, Wei ZC, Deng YY, Guo JX, and Zhang MW. 2015. Effect of degree of milling on phenolic profiles and cellular antioxidant activity of whole brown rice. Food Chemistry 185:318-325 DOI: 10.1016/j.foodchem.2015.03.151.

Liu Y, Hsieh F, Heymann H, and Huff HE. 2010. Effect of process conditions on the physical and sensory properties of extruded oat-corn puff. Journal of Food Science 65(7):1253-1259 DOI: 10.1111/j.1365-2621.2000.tb10274.x.

López-Alarcón C and Denicola A. 2013. Evaluating the antioxidant capacity of natural products: a review on;chemical and cellular-based assays. Analytica Chimica Acta 763(3):1-10 DOI: 10.1016/j.aca.2012.11.051

Malav OP, Sharma BD, Kumar RR, Talukder S, Ahmed SR, and Irshad A. 2016. Quality characteristics and storage stability of functional mutton patties incorporated with red kidney bean powder. Indian Journal of Small Ruminants 22(1):83-91 DOI: 10.5958/09739718.2016.00024.6.

Mitchell DC, Lawrence FR, Hartman TJ, and Curran JM. 2009. Consumption of Dry Beans, Peas, and Lentils Could Improve Diet Quality in the US Population. Journal of the American Dietetic Association 109(5):909-913 DOI: 10.1016/j.jada.2009.02.029.

Muttakin S, Kim MS, and Lee DU. 2015. Tailoring physicochemical and sensorial properties of defatted soybean flour using jet-milling technology. Food Chemistry 187:106-111 DOI: 
10.1016/j.foodchem.2015.04.104.

539

540

541

542

543

544

545

546

547

548

549

550

551

552

553

554

555

556

557

558

Ngah WSW, and Hanafiah MAKM. 2008. Adsorption of copper on rubber (Hevea brasiliensis) leaf powder: Kinetic, equilibrium and thermodynamic studies. Biochemical Engineering Journal 39(3):521-530 DOI: 10.1016/j.bej.2007.11.006.

Noeline BF, Manohar DM, and Anirudhan TS. 2005. Kinetic and equilibrium modelling of lead (II) sorption from water and wastewater by polymerized banana stem in a batch reactor. Separation \& Purification Technology 45(2):131-140 DOI: 10.1016/j.seppur.2005.03.004.

Oliveira GR, Santos AV, Lima AS, Soares CMF, Leite MS. 2015. Neural modelling in adsorption column of cholesterol-removal efficiency from milk. LWT - Food Science and Technology 64(2):632-638 DOI: 10.1016/j.lwt.2015.05.051.

Phat C, Hua L, Lee DU, Moon BK, Yoo YB, and Chan L. 2015. Characterization of Hericium erinaceum powders prepared by conventional roll milling and jet milling. Journal of Food Engineering 145:19-24 DOI: 0.1016/j.jfoodeng.2014.08.001.

Prokopov, TV. 2014. Utilization of by-products from fruit and vegetable processing: A review. Journal of Food and Packaging Science, Technique and Technologies 3:49-54.

Raghavendra SN, Swamy SRR, Rastogi NK, Raghavarao KSMS, Kumar S, and Tharanathan RN. 2006. Grinding characteristics and hydration properties of coconut residue: A source of dietary fiber. Journal of Food Engineering 72(3):281-286 DOI: 10.1016/j.jfoodeng.2004.12.008.

Roginsky V, and Lissi EA. 2005. Review of methods to determine chain-breaking antioxidant activity in food. Food Chemistry 92(2): 235-254 DOI: 
559

560

561

562

563

564

565

566

567

568

569

570

571

572

573

574

575

576

577

578

579

doi.org/10.1016/j.foodchem.2004.08.004.

Salehi E, Afshar S, Mehrizi MZ, Chehrei A, and Asadi M. 2018. Direct reduction of blood serum cholesterol using Thymus vulgaris L.: Preliminary biosorption study. Process Biochemistry 67:155-164 DOI: 10.1016/j.procbio.2018.01.023.

Shi L, Li WH, Sun JJ, Qiu YY, Wei XP, Luan GZ, Hu YY, and Tatsumib E. 2016. Grinding of maize: The effects of fine grinding on compositional, functional and physicochemical properties of maize flour. Journal of Cereal Science 64:25-30 DOI: 10.1016/j.jcs.2015.11.004.

Singh N, and P. S R. 2004. Free radical scavenging activity of an aqueous extract of potato peel. Food Chemistry 85(4): 611-616 DOI: doi.org/10.1016/j.foodchem.2003.07.003.

Soh HS, Kim CS, and Lee SP. 2003. A new in vitro assay of cholesterol adsorption by food and microbial polysaccharides. Journal of Medicinal Food 6:225 DOI: $10.1089 / 10966200360716643$.

Swami G, Gupta K, Kymonil KM, and Saraf S. 2010. Soyabean powder as a novel diluent in tablet formulation of simvastatin. Pharmaceutical Sciences 72(4):426-430 DOI: 10.4103/0250474X.73909.

Tan XY, Zhang BJ, Chen L, Li X, Li L, and Xie FW. 2015. Effect of planetary ball-milling on multi-scale structures and pasting properties of waxy and high-amylose cornstarches. Innovative Food Science \& Emerging Technologies 30:198-207 DOI: 10.1016/j.ifset.2015.03.013.

Fu XW, Huck D, Makein L, Armstrong B, Willen U, and Freeman T. 2012. Effect of particle shape 

10.1016/j.partic.2011.11.003.

582

583

584

Yu GY, Bei J, Zhao J, Li QH, and Cheng C. 2018. Modification of carrot (Daucus carota Linn. var. sativa Hoffm.) pomace insoluble dietary fiber with complex enzyme method, ultrafine comminution, and high hydrostatic pressure. Food Chemistry 257:333-340 DOI: 10.1016/j.foodchem.2018.03.037.

Zhao XY, Du FL, Zhu QJ, Qiu DL, Yin WJ, and Ao Q. 2010. Effect of superfine pulverization on properties of Astragalus membranaceus powder. Powder Technology 203(3):620-625 DOI: 10.1016/j.powtec.2010.06.029.

Zhao XY, Yang ZB, Gai GS, and Yang YF. 2009a. Effect of superfine grinding on properties of ginger powder. Journal of Food Engineering 91(2):217-222 DOI: 10.1016/j.jfoodeng.2008.08.024.

Zhao XY, Zhu HT, Zhang GX, and Tang WD. 2015. Effect of superfine grinding on the physicochemical properties and antioxidant activity of red grape pomace powders. Powder Technology 286:838-844 DOI: 10.1016/j.powtec.2015.09.025.

Zhao XY, Ao Q, Yang LW, Yang YF, Sun JC, and Gai GS. 2009b. Application of superfine pulverization technology in biomaterial industry. Journal of the Taiwan Institute of Chemical Engineers 40(3):337-343 DOI: 10.1016/j.jtice.2008.10.001.

Zhu FM, Du B, and Xu BJ. 2015. Superfine grinding improves functional properties and antioxidant capacities of bran dietary fibre from Qingke (hull-less barley) grown in Qinghai-Tibet Plateau, China. Journal of Cereal Science 65:43-47 DOI: 
601

doi.org/10.1016/j.jcs.2015.06.006.

602 Zhu KX, Huang S, Peng W, Qian HF, and Zhou HM. 2010. Effect of ultrafine grinding on 603 hydration and antioxidant properties of wheat bran dietary fiber. Food Research 604 International 43(4):943-948 DOI: 10.1016/j.foodres.2010.01.005.

605 Žilić S, Akıllığlu HG, Serpen A, Perić V, and Gökmen V. 2013. Comparisons of phenolic 606 compounds, isoflavones, antioxidant capacity and oxidative enzymes in yellow and black 607 soybeans seed coat and dehulled bean. European Food Research \& Technology 608 237(3):409-418 DOI: 10.1007/s00217-013-2005-y. 


\section{Figure 1}

SEM images of BKBP with different particle sizes.

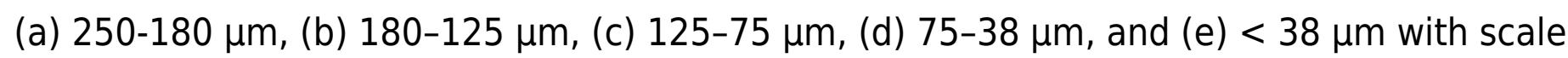

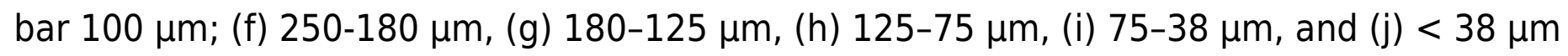
with scale bar $10 \mu \mathrm{m}$.

*Note: Auto Gamma Correction was used for the image. This only affects the reviewing manuscript. See original source image if needed for review. 

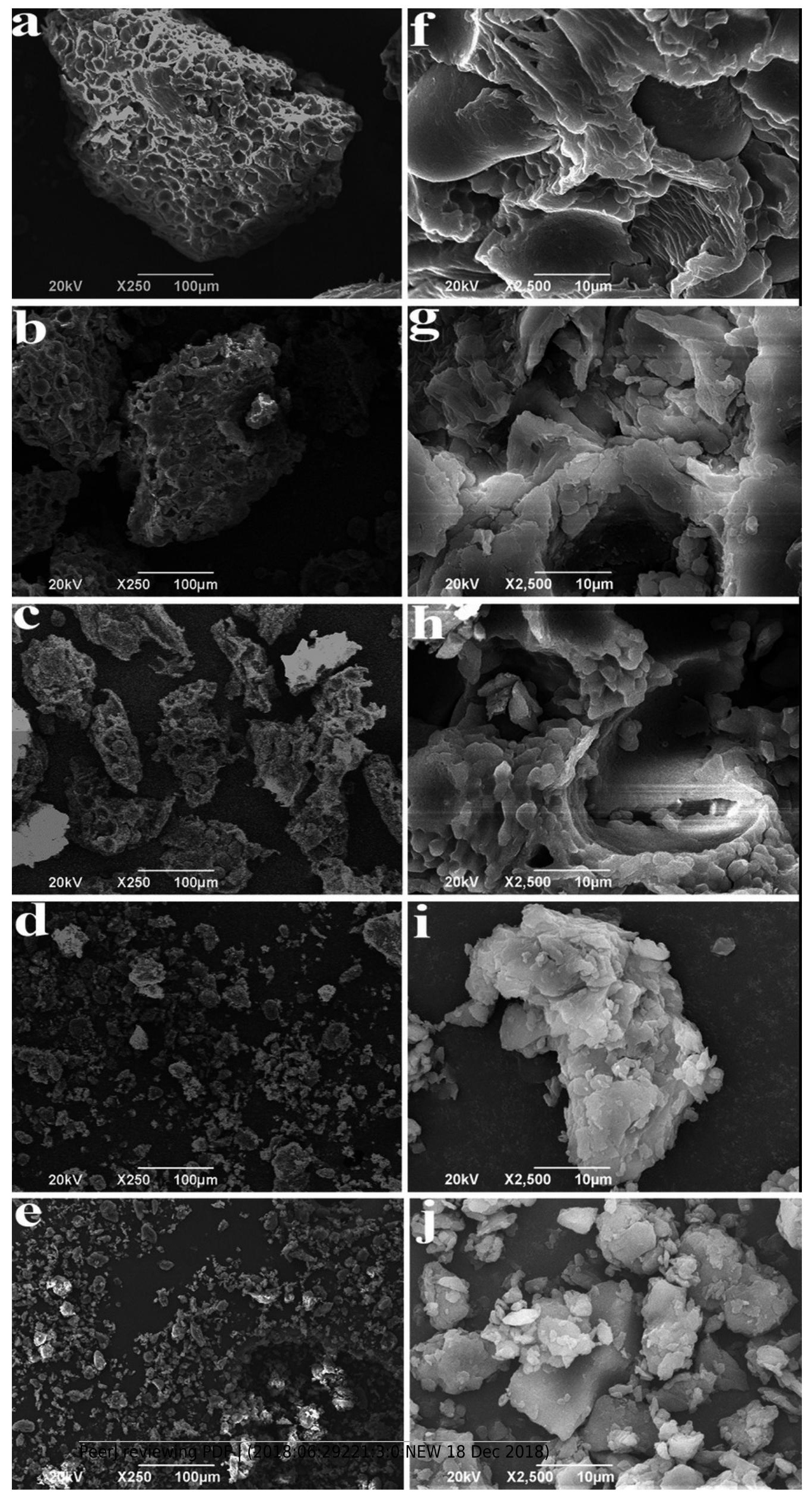
Figure 2

Hydration properties of BKBP with particle sizes of 250-180, 180-125, 125-75, 75-38, and $<38 \mu \mathrm{m}$ for soaking time $10-60 \mathrm{~min}$.

(a) water holding capacity (g/g); (b) water-retention capacity (g/g). 

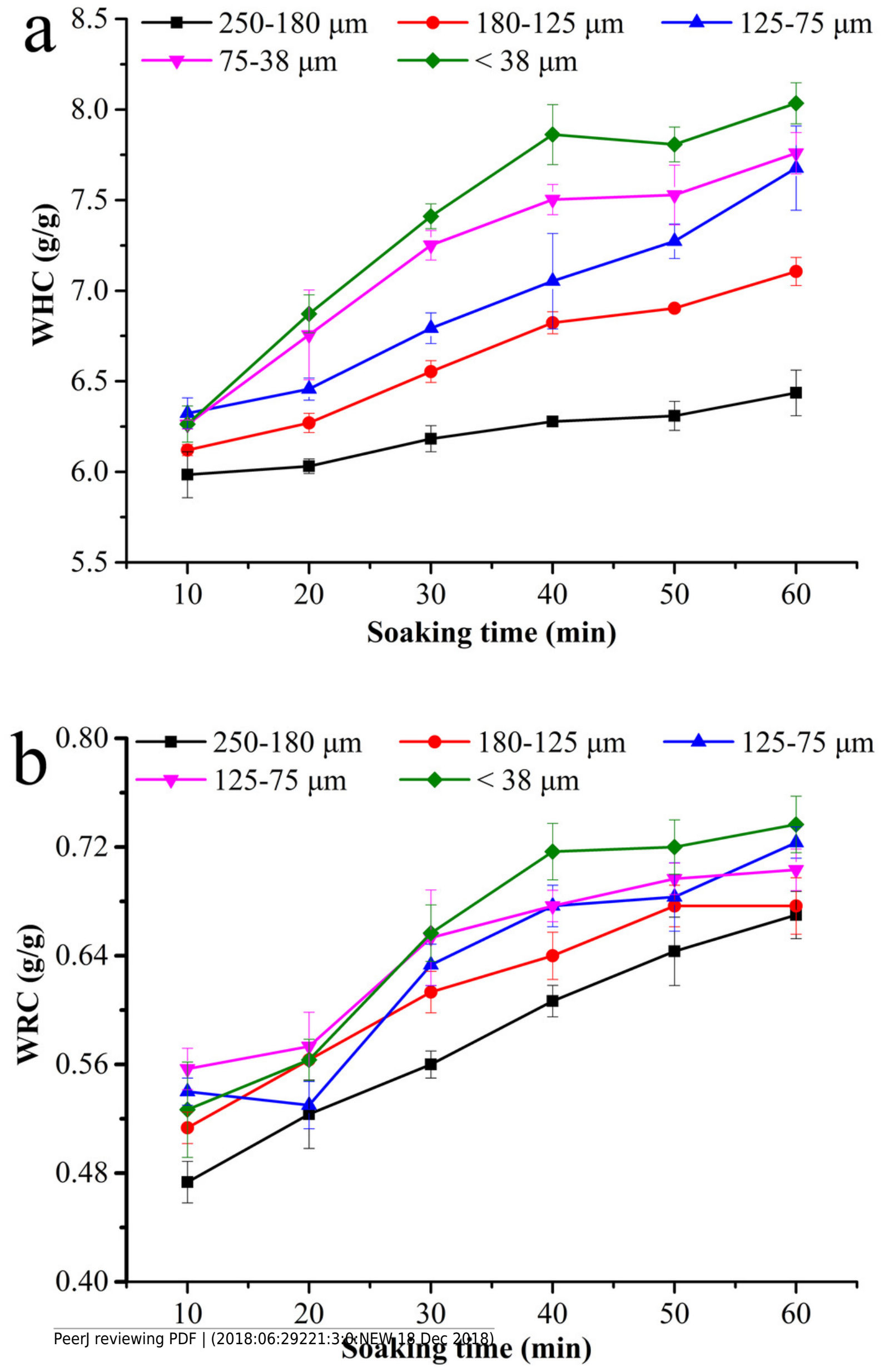
Figure 3

Average DSC curves of BKBP with particle sizes of 250-180, 180-125, 125-75, 75-38, and $<38 \mu \mathrm{m}$.

DSC recoded from 20 to $220^{\circ} \mathrm{C}$ at a heating rate of $10^{\circ} \mathrm{C} / \mathrm{min}$.

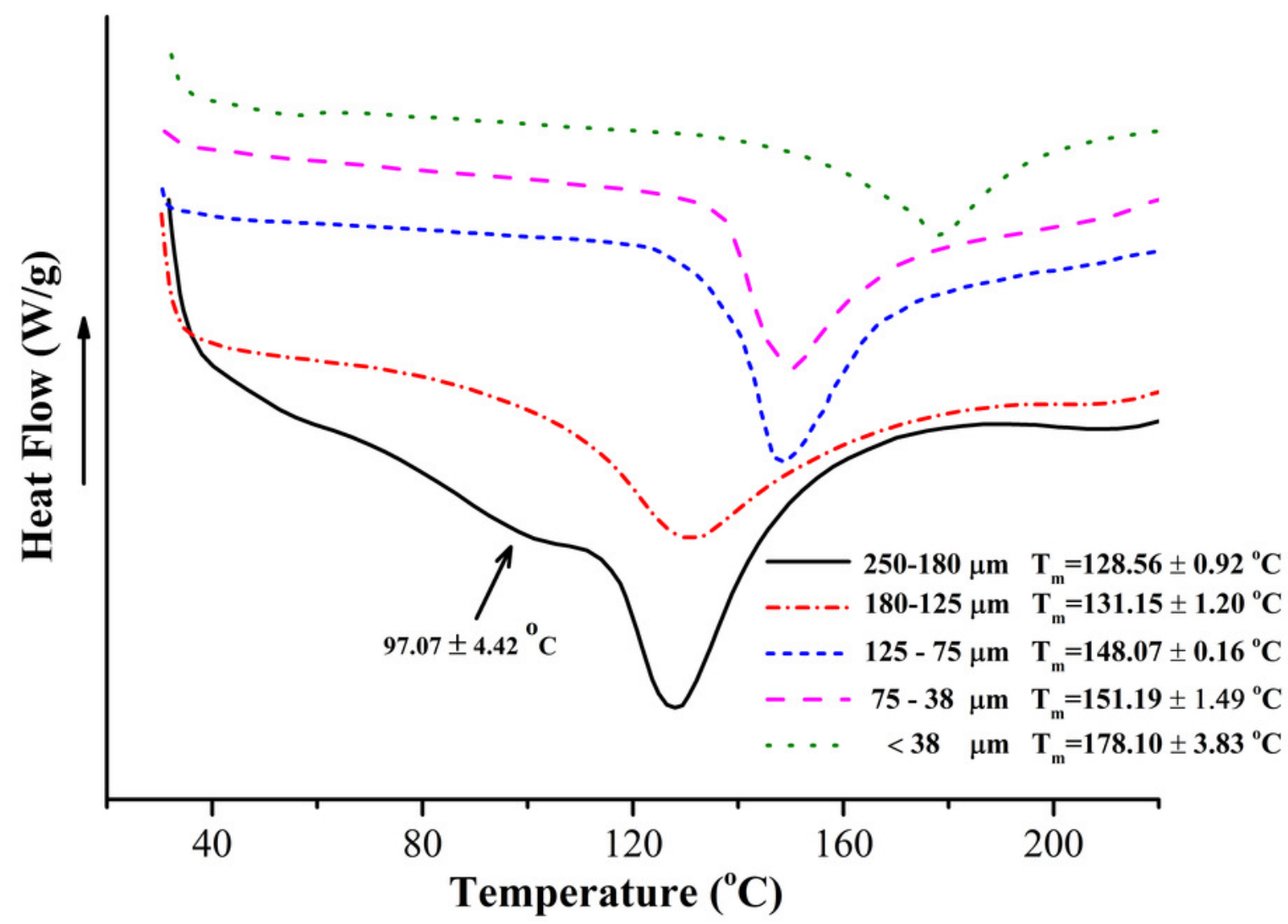




\section{Figure 4}

Cholesterol adsorption capacity of BKBP.

(a) different particle size, (b) powder dosage, (c) initial cholesterol concentration, (d) absorption time, and (e) temperature. (f) Separation factor $R_{L}$ for the Langmuir isotherm. 


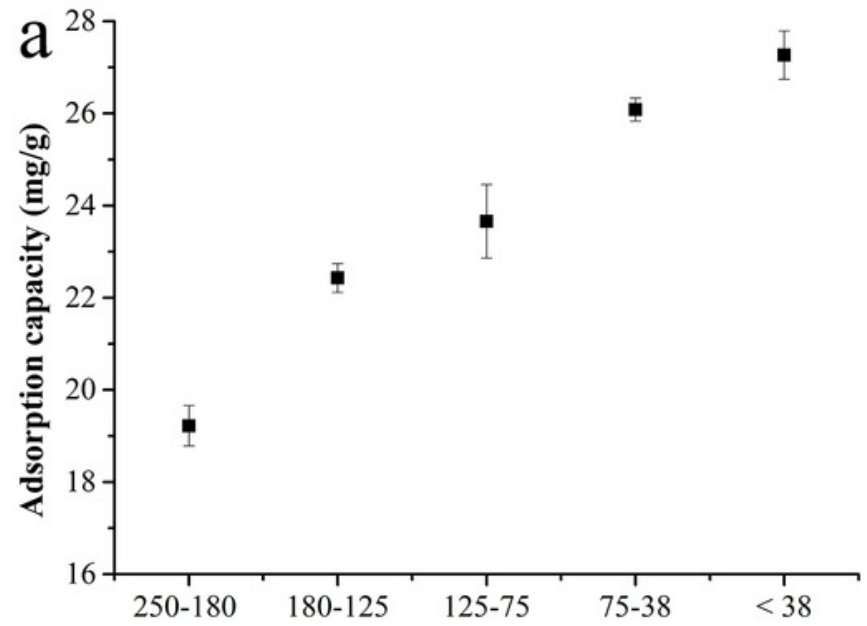

Powder particles $(\mu \mathrm{m})$
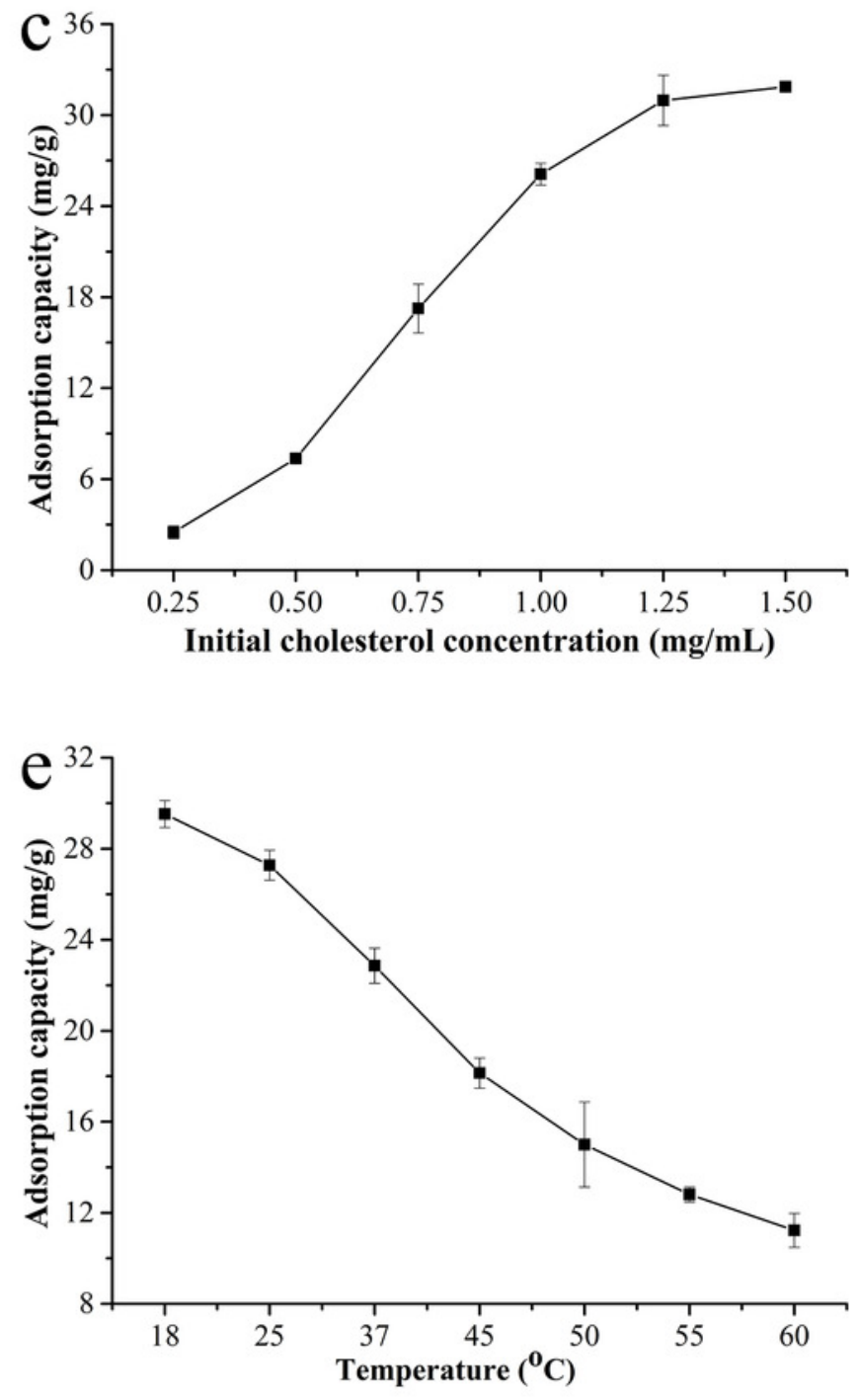
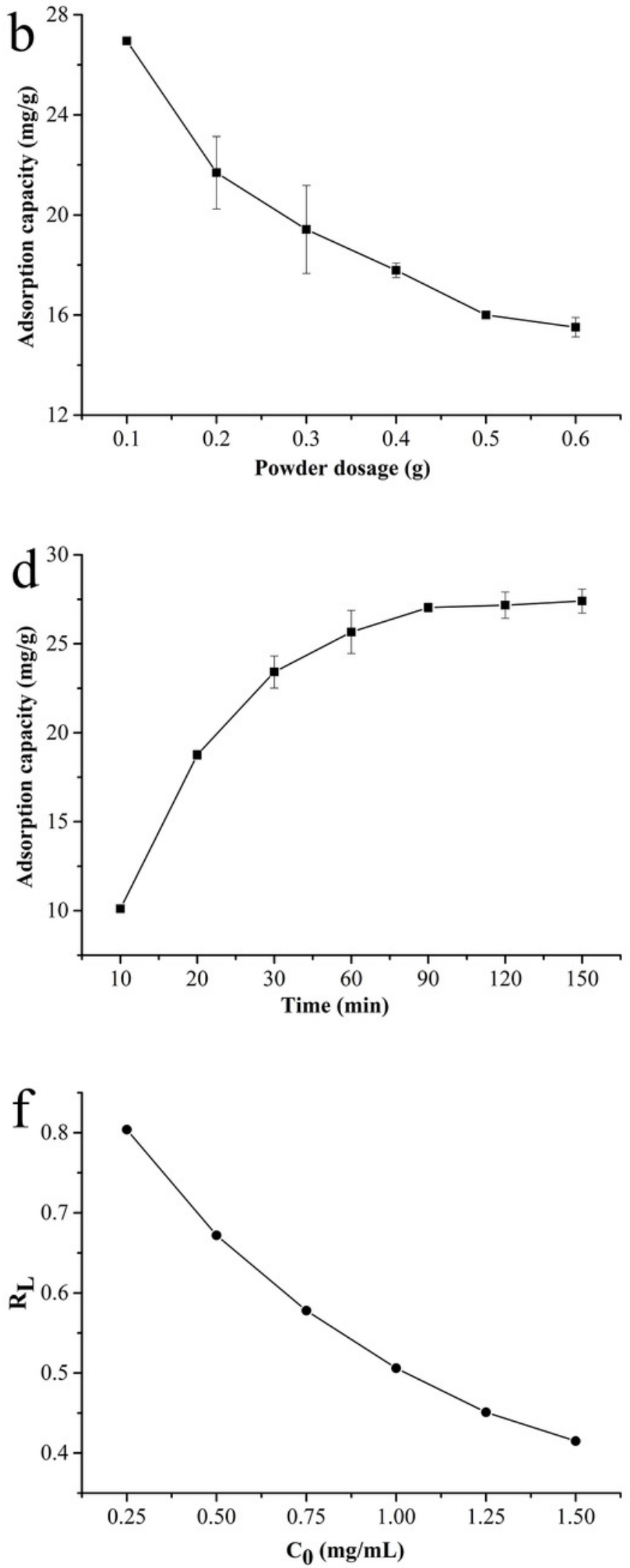
Figure 5

Antioxidant properties of BKBP with particle sizes of 250-180, 180-125, 125-75, 75-38, and $<38 \mu \mathrm{m}$.

(a) DPPH - scavenging activity (\%), (b) hydroxyl radical-scavenging activity (\%), and (c) ferrous ion-chelating activity (\%).
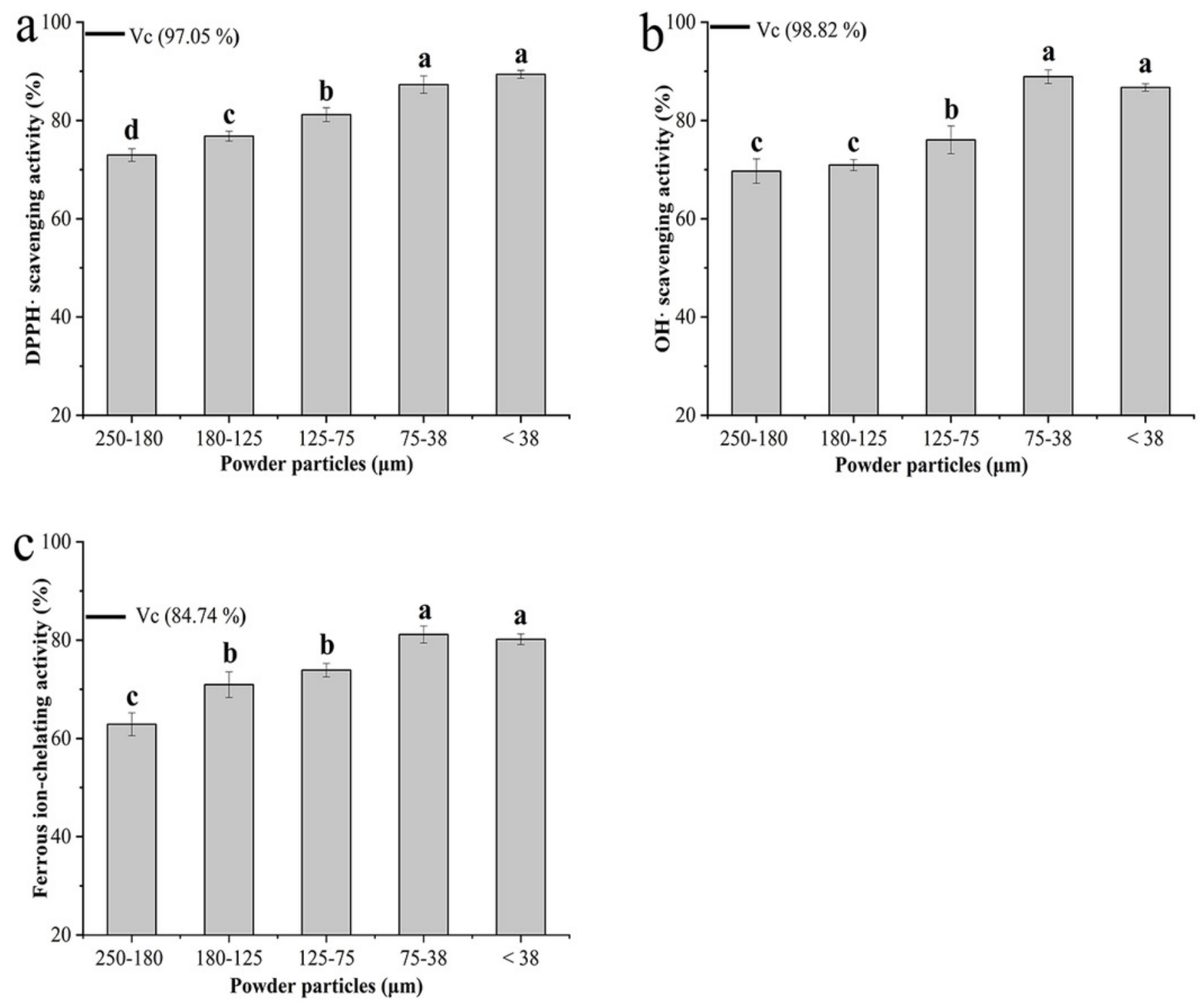


\section{Table $\mathbf{1}$ (on next page)}

Particle size distributions and specific surface areas of the BKBP obtained from the laser diffraction method.

The results were expressed as Mean \pm standard deviation. Data in the same column with different letters were significantly different $(P<0.05)$. 


\begin{tabular}{|c|c|c|c|c|c|}
\hline \multirow{2}{*}{$\begin{array}{l}\text { Powder particles } \\
\qquad(\mu \mathrm{m})\end{array}$} & \multicolumn{4}{|c|}{$\begin{array}{l}\text { Equivalent diameter particles accounted for by measuring the proportion } \\
\qquad(\mu \mathrm{m})\end{array}$} & \multirow{2}{*}{$\begin{array}{c}\text { Specific } \\
\text { surface area } \\
\left(\mathbf{m}^{2} / \mathbf{g}\right) \\
\end{array}$} \\
\hline & $\mathrm{D}_{10}$ & $\mathrm{D}_{50}$ & $\mathrm{D}_{90}$ & $\mathrm{D}_{[4,3]}$ & \\
\hline $250-180$ & $54.366 \pm 2.382^{\mathrm{a}}$ & $257.167 \pm 5.252^{\mathrm{a}}$ & $500.742 \pm 5.667^{\mathrm{a}}$ & $226.658 \pm 3.875^{\mathrm{a}}$ & $0.125 \pm 0.010^{\mathrm{d}}$ \\
\hline $180-125$ & $24.460 \pm 2.029^{b}$ & $217.081 \pm 3.820^{b}$ & $362.479 \pm 6.836^{b}$ & $214.801 \pm 7.033^{b}$ & $0.133 \pm 0.009^{d}$ \\
\hline $125-75$ & $25.671 \pm 0.337^{b}$ & $140.998 \pm 3.799^{c}$ & $255.877 \pm 2.529^{c}$ & $146.407 \pm 5.660^{c}$ & $0.176 \pm 0.017^{\mathrm{c}}$ \\
\hline 75-38 & $9.694 \pm 1.424^{\mathrm{c}}$ & $36.594 \pm 1.328^{d}$ & $86.295 \pm 5.650^{d}$ & $45.962 \pm 3.114^{\mathrm{d}}$ & $0.297 \pm 0.015^{b}$ \\
\hline$<38$ & $4.810 \pm 0.533^{\mathrm{d}}$ & $20.706 \pm 2.025^{\mathrm{e}}$ & $51.331 \pm 4.988^{\mathrm{e}}$ & $24.835 \pm 5.494^{\mathrm{e}}$ & $0.520 \pm 0.026^{\mathrm{a}}$ \\
\hline
\end{tabular}




\section{Table 2 (on next page)}

Color and flow properties of the BKBP.

The results were expressed as Mean \pm standard deviation. Data in the same column with different letters were significantly different $(P<0.05)$. 


\begin{tabular}{|c|c|c|c|c|c|c|c|}
\hline \multirow{2}{*}{$\begin{array}{c}\text { Powder } \\
\text { particles } \\
(\mu \mathrm{m})\end{array}$} & \multicolumn{3}{|c|}{ Color } & \multicolumn{4}{|c|}{ Flow property } \\
\hline & $L^{*}$ & $a^{*}$ & $b^{*}$ & $\begin{array}{l}\text { Bulk density } \\
\qquad(\mathrm{g} / \mathrm{mL})\end{array}$ & $\begin{array}{c}\text { Tapped density } \\
(\mathrm{g} / \mathrm{mL})\end{array}$ & $\begin{array}{c}\text { Angle of repose } \\
\left({ }^{\circ}\right)\end{array}$ & $\begin{array}{c}\text { Angle of slide } \\
\left({ }^{\circ}\right)\end{array}$ \\
\hline $250-180$ & $90.389 \pm 0.119^{d}$ & $-4.748 \pm 0.127^{d}$ & $30.654 \pm 0.872^{b}$ & $0.439 \pm 0.022^{\mathrm{a}}$ & $1.435 \pm 0.525^{\mathrm{c}}$ & $51.878 \pm 1.102^{\mathrm{a}}$ & $45.452 \pm 0.833^{\mathrm{a}}$ \\
\hline $180-125$ & $91.331 \pm 0.312^{\mathrm{c}}$ & $-3.583 \pm 0.008^{c}$ & $19.092 \pm 1.028^{c}$ & $0.416 \pm 0.018^{\mathrm{ab}}$ & $1.684 \pm 0.329^{b c}$ & $49.013 \pm 0.330^{\mathrm{b}}$ & $41.653 \pm 0.243^{b}$ \\
\hline $125-75$ & $91.598 \pm 0.006^{\mathrm{bc}}$ & $-3.216 \pm 0.052^{\mathrm{c}}$ & $15.805 \pm 1.150^{\mathrm{d}}$ & $0.396 \pm 0.009^{\mathrm{b}}$ & $1.971 \pm 0.070^{\mathrm{bc}}$ & $49.968 \pm 1.029^{b}$ & $38.280 \pm 2.049^{\circ}$ \\
\hline 75-38 & $91.974 \pm 0.228^{\mathrm{a}}$ & $-3.550 \pm 0.309^{\mathrm{b}}$ & $20.722 \pm 0.877^{c}$ & $0.369 \pm 0.010^{c}$ & $2.214 \pm 0.104^{\mathrm{ab}}$ & $46.784 \pm 0.144^{c}$ & $35.155 \pm 0.638^{\mathrm{d}}$ \\
\hline$<38$ & $91.711 \pm 0.015^{\mathrm{ab}}$ & $-2.609 \pm 0.205^{\mathrm{a}}$ & $35.653 \pm 0.649^{\mathrm{a}}$ & $0.364 \pm 0.005^{\mathrm{c}}$ & $2.645 \pm 0.220^{\mathrm{a}}$ & $43.282 \pm 0.936^{\mathrm{d}}$ & $33.259 \pm 1.550^{\mathrm{d}}$ \\
\hline
\end{tabular}




\section{Table 3 (on next page)}

The results of fitted isothermal adsorption models and their parameters. 


\begin{tabular}{ccccc}
\hline Isotherm model & \multicolumn{2}{c}{ Parameters } & Equation & $\mathbf{R}^{2}$ \\
\hline \multirow{2}{*}{ Langmuir isotherm } & $\mathrm{q}_{\mathrm{m}} /(\mathrm{mg} / \mathrm{g})$ & 53.476 & $\frac{1}{\mathrm{q}_{\mathrm{e}}}=\frac{0.0192}{\mathrm{C}_{\mathrm{e}}}+0.0187$ & 0.911 \\
& $\mathrm{~K}_{\mathrm{L}} /(\mathrm{mL} / \mathrm{mg})$ & 0.974 & & \\
Freundlich isotherm & $\mathrm{K}_{\mathrm{F}} /(\mathrm{mg} / \mathrm{g})$ & 0.161 & $\lg \mathrm{q}_{\mathrm{e}}=0.697 \lg \mathrm{C}_{\mathrm{e}}+1.449$ & 0.914 \\
\hline
\end{tabular}

